\title{
Programa de triagem neonatal para fibrose cística no estado do Paraná: avaliação após 30 meses de sua implantação
}

\author{
Neonatal cystic fibrosis screening program in the state of Paraná: \\ evaluation 30 months after implementation
}

\author{
Grégor P. Chermikoski Santos ${ }^{1}$, Mouseline T. Domingos ${ }^{2}$, Ehrenfried O. Wittig ${ }^{3}$, \\ Carlos A. Riedi ${ }^{4}$, Nelson A. Rosário ${ }^{5}$
}

\section{Resumo}

Objetivos: Apresentar e analisar os resultados da implantação do Programa Nacional de Triagem Neonatal em Fibrose Cística, no Paraná, após 30 meses do seu início.

Métodos: Foi realizado um estudo descritivo com análise dos dados da triagem feita em aproximadamente $98 \%$ dos recém-nascidos entre setembro de 2001 e abril de 2004 no laboratório do Serviço de Triagem Neonatal da Fundação Ecumênica de Proteção ao Excepcional do Paraná. As amostras de sangue para o "teste do pezinho" foram coletadas na alta hospitalar, idealmente entre o segundo e sexto dias de vida, com o envio dos papéis-filtro para a dosagem de tripsina imunorreativa por imunofluorimetria. Crianças com valores da dosagem de tripsina imunorreativa $\geq 70 \mathrm{ng} / \mathrm{ml}$ em duas amostras distintas, nos primeiros 30 dias de vida, foram submetidas à determinação da condutividade do suor pelo método de Wescor. Com o resultado maior que $50 \mathrm{mMol} / \mathrm{l}$ procedeu-se à dosagem quantitativa de cloro e/ou sódio no suor (iontoforese por pilocarpina).

Resultados: De 456.982 exames realizados, 4.028 (0,9\%) crianças apresentaram a primeira dosagem de tripsina imunorreativa acima do ponto de corte estabelecido. Dessas, 478 (12,5\%) tiveram uma segunda amostra de sangue com dosagem de tripsina imunorreativa acima de $70 \mathrm{ng} / \mathrm{ml}$, das quais, após a realização do teste de suor por condutividade, $56(11,7 \%)$ crianças foram encaminhadas para ambulatórios especializados com resultado acima de $50 \mathrm{mMol} / \mathrm{l}$ e $48(0,01 \%$ do total de triagens) tiveram o diagnóstico de fibrose cística confirmado. A incidência foi de 1:9.520 em nosso estado, embora algumas crianças ainda não tenham completado a investigação.

Conclusões: A triagem neonatal para fibrose cística no estado do Paraná, de acordo com as normas do Ministério da Saúde, foi uma iniciativa pioneira no Brasil. Realizou-se o diagnóstico precocemente em muitos pacientes, mesmo os assintomáticos, fato que representa um desafio à melhora no prognóstico dessa doença fatal.

J Pediatr (Rio J). 2005;81(3):240-4: Fibrose cística, triagem neonatal, tripsina imunorreativa, Brasil.

\begin{abstract}
Objectives:To present and analyze the results of the National Neonatal Cystic Fibrosis Screening Program in Paraná, 30 months after its implementation.

Methods: This is a descriptive study, with an analysis of the data from the screening of around $98 \%$ of all neonates in the period from September 2001 to April 2004, undertaken at the Neonatal Screening Program laboratory of the Fundação Ecumênica de Proteção ao Excepcional do Paraná. Blood samples for the Guthrie test were collected on hospital discharge, ideally between the second and sixth days postpartum, and filter papers were sent for immunoreactive trypsin assay by the immunofluorometric method. Children whose immunoreactive trypsin assay results were $\geq 70 \mathrm{ng} / \mathrm{ml}$ for two distinct samples during the first 30 days of life, were referred for sweat conductivity testing by the Wescor method. In cases when the result was greater than $50 \mathrm{mMol} / \mathrm{l}$ quantitative chlorine and/or sodium in sweat was assayed (iontophoresis with pilocarpine).
\end{abstract}

Results: From a total of 456,982 tests, 4,028 (0.9\%) children presented a first immunoreactive trypsin assay above the cutoff point set. Four hundred and seventy-eight of these $(12.5 \%)$ also had a second blood sample assayed with immunoreactive trypsin above 70 $\mathrm{ng} / \mathrm{ml}$ and $56(11.7 \%)$ of these were referred to specialized clinics after their sweat conductivity test results were above $50 \mathrm{mMol} / \mathrm{l}$ and 48 $(0.01 \%$ of the total number of children screened) had a diagnosis of cystic fibrosis confirmed. The incidence for the state of Paraná was $1: 9,520$, although some children have not yet been fully investigated.

Conclusions: Neonatal screening for cystic fibrosis in the State of Paraná, in accordance with Health Ministry directives, was a pioneering initiative for Brazil. Many patients were diagnosed early, even asymptomatic ones, which is a challenge to improving prognosis with this fatal disease.

J Pediatr (Rio J). 2005;81(3):240-4: Cystic fibrosis, neonatal screening, immunoreactive trypsin, Brazil.

1. Médico residente (R4) em Pneumologia Pediátrica, Universidade Federal do Paraná (UFPR), Curitiba, PR.

2. Bioquímica, chefe do laboratório de pesquisas da Fundação Ecumênica de Proteção ao Excepcional (FEPE/PR), Curitiba, PR.

3. Professor adjunto, Departamento de Clínica Médica, UFPR, Curitiba, PR.

4. Mestre. Professor substituto, Departamento de Pediatria, UFPR, Curitiba, PR.

5. Doutor. Professor titular, Departamento de Pediatria, UFPR, Curitiba, PR.

Artigo submetido em 31.08.04, aceito em 27.01.05.

Como citar este artigo: Santos GP, Domingos MT, Wittig EO, Riedi CA, Rosário NA. Programa de triagem neonatal para fibrose cística no estado do Paraná: avaliação após 30 meses de sua implantação. J Pediatr (Rio J). 2005;81:240-4. 


\section{Introdução}

A fibrose cística (FC), ou mucoviscidose, é uma doença genética autossômica recessiva. Há mais de 1.000 mutações descritas responsáveis pela transmissão da doença, cuja incidência varia de 1:2.000 a 1:10.000 entre povos de origem caucasóide, onde a doença se manifesta com maior freqüência. No Brasil, estima-se que a incidência da doença seja de 1:10.000 nascidos vivos, embora haja variação na freqüência das mutações em diferentes regiões geográficas, o que possivelmente refletiria também uma diferente prevalência da doença ${ }^{1}$. Nos EUA e países da Europa, seu diagnóstico é feito precocemente, antes do primeiro ano de vida, o que proporciona a essas crianças serem tratadas e monitoradas quanto a variáveis que influenciam diretamente no prognóstico da doença, como, por exemplo, o acompanhamento da curva pondero-estatural e a presença de colonização de vias aéreas superiores por patógenos, que têm relação íntima com pior prognóstico da doença ${ }^{2}$.

A partir do ano de 2001, com a aprovação do Programa Nacional de Triagem Neonatal e com a implantação do programa pelo laboratório da Fundação Ecumênica de Proteção ao Excepcional (FEPE-PR), concretizou-se a realização da Triagem para Fibrose Cística no Paraná. Antes da instituição do Programa Nacional de Triagem Neonatal para Fibrose Cística, os dados traziam uma triste realidade, mostrando que a média da idade ao diagnóstico da doença situava-se em torno de 1,6 anos ${ }^{3}$. Essas crianças, no momento do diagnóstico, já apresentavam desnutrição importante e colonização precoce por germes habituais à FC, sem contar toda a morbidade envolvida até a realização do diagnóstico. A média de internações por ano era de uma a quatro por criança, com duração aproximada de 10 a 60 dias $^{3}$.

Ao realizar a triagem neonatal para determinada doença, deve-se levar em consideração, principalmente, a relação custo-benefício para sua população, embora não seja condição necessária, segundo critérios da Organização das Nações Unidas (ONU).

Os principais objetivos do estudo foram mostrar os resultados da implantação do Programa Nacional de Triagem Neonatal em Fibrose Cística no Paraná e fazer uma análise sobre os dados obtidos após 30 meses do seu início.

\section{Métodos e casuística}

O estudo foi descritivo com análise dos dados fornecidos pela FEPE/PR e dos prontuários dos pacientes em acompanhamento no Hospital de Clínicas no período de setembro de 2001 a abril de 2004. O protocolo foi aprovado pelo Comitê de Ética em Pesquisas em Seres Humanos do Hospital de Clínicas da Universidade Federal do Paraná.

A população estudada incluiu todas as crianças triadas (cerca de $98 \%$ das crianças nascidas vivas) nesse período no estado do Paraná.

As amostras de sangue foram obtidas conforme protocolo já estabelecido da triagem neonatal para doenças como fenilcetonúria, hipotireoidismo congênito e hemo- globinopatias, preferencialmente realizadas após as primeiras 48 horas de vida, por punção do calcanhar do recém-nascido com lanceta estéril e colheita da gota de sangue em papel-filtro. Após secagem, as amostras foram enviadas à FEPE via correio, com sede localizada na cidade de Curitiba.

Na FEPE, esses papéis-filtro foram picotados com instrumento padrão em amostras com $3 \mathrm{~mm}$ de diâmetro, a partir das quais procedeu-se à leitura quantitativa da tripsina imunorreativa (TIR) em sangue total, em duplicata, por sistema automatizado através do método imunofluorimétrico (Kit autoDELFIA ${ }^{T M}$ ). Utilizou-se, como ponto de corte para a primeira dosagem da TIR, o valor de $70 \mathrm{ng} / \mathrm{ml}$. Convocou-se para nova colheita de sangue todas as crianças cuja primeira dosagem da TIR, em duas amostras, estivesse acima do ponto de corte estabelecido. As dosagens da TIR foram realizadas no primeiro mês de vida.

Se a segunda dosagem da TIR tivesse valor igual ou maior a $70 \mathrm{ng} / \mathrm{ml}$, era realizado o teste da condutividade do suor.

Assumiu-se como ponto de corte para o teste da condutividade do suor o valor de $50 \mathrm{mMol} / \mathrm{I}^{4}$. Procedeu-se o teste de suor (condutividade), com passagem de corrente iontoforética pelo antebraço da criança e posterior colheita do suor, utilizando o Macroduct Sweat Collection System ${ }^{\circledR}$, e leitura por meio do Wescor's Sweat Check Conductivity Analyser.

Todas as crianças que apresentaram condutividade com valores acima do ponto de corte foram encaminhadas para a realização do teste de suor, com estimulação através de iontoforese por pilocarpina e dosagem de sódio $\left(\mathrm{Na}^{+}\right)$por fotometria de chama e/ou cloro $\left(\mathrm{Cl}^{-}\right)$, padrãoouro para o diagnóstico da doença. Foi atribuído o diagnóstico de $\mathrm{FC}$ às crianças com valores de eletrólitos no suor acima de $60 \mathrm{mEq} / \mathrm{l}$ em duas ocasiões, quando foram iniciados o esclarecimento da doença e o aconselhamento genético, bem como o tratamento.

\section{Resultados}

Do total de triagens realizadas no estado do Paraná no período de agosto de 2001 a abril de 2004 (456.982), obteve-se um número de 4.028 crianças cujo primeiro resultado da dosagem da TIR foi acima do ponto de corte, aproximadamente $0,9 \%$ do total de crianças triadas.

Todas as crianças foram reconvocadas, porém somente 3.815 compareceram para a realização do novo exame. Das crianças reconvocadas, $478(12,5 \%)$ tiveram o segundo resultado da TIR acima do ponto de corte, o que representa $87,5 \%$ de falso-positivos na primeira dosagem. A análise da condutividade do suor identificou 63 crianças com valores acima de $50 \mathrm{mMol} / \mathrm{l}$. Dessas, 56 foram encaminhadas aos centros especializados (outras sete estão em processo de reconvocação). A determinação quantitativa de eletrólitos no suor em duas ocasiões confirmou o diagnóstico de FC em $48(0,01 \%$ do total) crianças, as quais se encontram em acompanhamento ambulatorial, uma média de 18 casos/ ano. Esses valores revelam uma incidência da doença de 
1:9.520 nascimentos no estado do Paraná, mas deve-se levar em consideração que algumas crianças não haviam completado a investigação, o que poderia aumentar essa incidência.

O valor médio da primeira dosagem da TIR nessas 48 crianças foi de $172,4 \pm 79,6 \mathrm{ng} / \mathrm{dl}$, cuja amostra de sangue foi obtida, em média, aos 5,8 dias de vida. Na segunda dosagem da TIR realizada em 40 crianças, o valor médio foi de $170,3 \pm 82,5 \mathrm{ng} / \mathrm{dl}$. Nesta, a amostra de sangue foi colhida, em média, aos 22,4 dias de vida, alcançando o objetivo de se realizar a triagem nos primeiros 30 dias de vida da criança. O diagnóstico de FC foi confirmado após a realização das dosagens de eletrólitos no suor.

A média de peso ao nascimento foi de $3.074 \mathrm{~g}$, mas, no momento do diagnóstico, 16 (33,3\%) tinham peso e/ou estatura abaixo do terceiro percentil esperado para a idade.

Houve predomínio da raça branca ( $89 \%)$, e a relação masculino:feminino foi $1: 1$. Cinco pacientes tinham história familiar positiva, e $10 \%$ apresentaram íleo meconial.

\section{Discussão}

Não há consenso sobre a realização da triagem neonatal para $\mathrm{FC}$, pois existe a dúvida de que os benefícios não superem os custos e os efeitos indesejados. Até o momento, poucos países, como Austrália, Nova Zelândia, França, Áustria, Polônia, Estados Unidos e Inglaterra têm um programa Nacional de Triagem Neonatal, porém nem sempre o programa está uniformemente estabelecido em todo o território nacional ${ }^{5}$. Na maioria dos países, falta uma legislação específica e critérios para a orientação sobre como deve ser feita a triagem neonatal para FC.

Os critérios para a implantação de um programa de triagem neonatal, os quais são preenchidos pela FC, foram estabelecidos pela $\mathrm{OMS}^{6}$. No Brasil, a triagem neonatal para FC foi implantada com a publicação no Diário Oficial da União, em 07/06/2001, da portaria 822, que rege as normas para realização da triagem neonatal no país. No Paraná, coube à FEPE a implantação e aplicação da mesma. Essa portaria estabelece que, além da deteç̧ão dos casos suspeitos, deve ser realizada a confirmação diagnóstica, acompanhamento e tratamento dos pacientes.

São argumentos a favor da realização da triagem neonatal para FC os indiscutíveis ganhos em relação ao diagnóstico precoce, as repercussões sobre o estado nutricional e a prevenção à desnutrição, com suas implicações sobre o aparelho respiratório e cognitivo ${ }^{7-13}$. No Paraná, a média da idade de diagnóstico de FC era de 1,6 $\operatorname{anos}^{3}$. Com o advento da triagem neonatal, é possível a confirmação do diagnóstico no segundo mês de vida. Além disso, o número médio de diagnósticos no serviço aumentou de oito para 18 casos por ano ${ }^{3}$. Somam-se ainda benefícios como tratamento precoce em centros de referência, prevenção de complicações ${ }^{14}$, aconselhamento genético, além de permitir calcular a incidência, evitar a demora no diagnóstico e trazer melhor conhecimento sobre a história natural da doença ${ }^{12,13}$.
Há argumentos contra a realização da triagem neonatal, desde o medo e a ansiedade gerados no período de realização dos exames até a exclusão de uma criança falsopositiva ${ }^{15}$, e a descoberta de heterozigotos portadores do gene, nos programas de triagem que envolvem a pesquisa de mutações para $\mathrm{FC}^{16}$.

O diagnóstico pode ser feito em várias oportunidades: antenatal, quando já houver casos na família (por biópsia de vilosidade coriônica, seguida de análise genética), o que poderia reduzir a prevalência de FC após o aconselhamento genético ${ }^{17}$; no primeiro ano de vida, por manifestações precoces, como o íleo meconial; pela realização da triagem neonatal ou, finalmente, quando há manifestações clínicas da doença.

As crianças identificadas pela triagem neonatal no Paraná com diagnóstico confirmado de FC eram eutróficas ao nascimento, a maioria da raça branca, e a freqüência do íleo meconial foi semelhante ao observado por outros autores ${ }^{18}$.

O tripsinogênio, enzima produzida pelo pâncreas, normalmente chega à luz intestinal. Nos pacientes com FC, devido à obstrução dos ductos pancreáticos, impede a secreção da mesma e ocorre ativação para tripsina. Isso explica os valores elevados da enzima no sangue de crianças acometidas pela doença ${ }^{19}$, o que também ocorre em pacientes com suficiência pancreática ${ }^{20}$.

A colheita do sangue deve ser idealmente realizada entre o segundo e o sexto dia de vida, pois há uma queda crescente dos níveis da enzima com o passar dos dias ${ }^{21}$. A triagem realizada no Paraná consegue seguir essa recomendação, com altas taxas de cobertura de realização do teste e rapidez no envio das amostras.

Vários protocolos são usados na triagem neonatal para fibrose cística ${ }^{22}$. Há países que fazem apenas dosagens da TIR em duas ocasiões diferentes, seguidas pelo teste de suor, e outros que associam a pesquisa das principais mutações envolvidas na patogênese da doença durante a investigação. No Paraná, a opção de duas dosagens da TIR em ocasiões diferentes nos primeiros 30 dias de vida foi a escolhida, considerando que a mutação $\Delta \mathrm{F} 508$ ocorre em homozigose em apenas $26,3 \%$ dos pacientes com $\mathrm{FC}^{23}$. Isso significa que, se esse método fosse escolhido, o diagnóstico seria feito em apenas $1 / 4$ dos casos.

Uma dificuldade na realização da TIR é a falta de consenso quanto ao valor normal. O número de falsopositivos e falso-negativos depende do valor de corte escolhido. Quanto maior o valor do ponto de corte, maior a chance de ocorrerem falso-negativos, e quanto menor o ponto de corte, maior o número de falso-positivos. O valor de $70 \mathrm{ng} / \mathrm{ml}$ correspondente ao percentil 99,8 estabelecido por Hammond et al. ${ }^{24}$ confere ao teste sensibilidade em torno de $90 \%$ e uma especificidade de $98 \%$. Na experiência adquirida no Paraná com o protocolo TIR/TIR seguido de dosagem de eletrólitos no suor, houve aumento do número de diagnósticos e relato de apenas uma criança em que a doença não foi detectada. Essa criança não apresentou íleo meconial e os valores de TIR foram $70,8 \mathrm{ng} / \mathrm{ml}$ na primeira amostra e 48,2 ng/ml na segunda dosagem, realizada com 23 dias de vida. 
Alguns fatores como índices de Apgar baixos, obstrução intestinal e agenesia de ductos pancreáticos também podem elevar os valores da TIR, causando dificuldade na interpretação do resultado ${ }^{24}$. A repetição do exame nos primeiros 30 dias de vida da criança reduz o número de falso-positivos em torno de $90 \%$ e também evita que a queda crescente dos valores cause dificuldade de interpretação. Para Rock et al. ${ }^{21}$, não se pode esperar valores da TIR persistentemente elevados para a realização do teste de suor. Houve um alto número de falso-positivos à primeira dosagem da TIR, reduzido significativamente após a segunda dosagem e, mais ainda, após o teste de suor. Valores de sensibilidade, especificidade, valores preditivos positivo e negativo do teste não podem ser obtidos, pois não é conhecido o número de crianças com FC que não foram identificadas pelo protocolo de triagem.

A análise da condutividade é um teste de triagem que se correlaciona bem com a dosagem quantitativa de eletrólitos $^{4}$. Todas as crianças com diagnóstico de FC apresentaram valores elevados de condutividade no suor.

A percentagem de crianças diagnosticadas (considerando-se o número total de crianças triadas) após quase 3 anos da implantação da triagem neonatal para fibrose cística no Paraná é satisfatória, visto ter mais do que duplicado o número de diagnósticos por ano, porém ainda está aquém do valor estimado anteriormente pela freqüência da mutação em nosso estado23.

As principais dificuldades foram a padronização na colheita das amostras, envio do material ao centro de referência e, principalmente, na reconvocação de pacientes com exames alterados (em grande parte pela dificuldade de localização dos mesmos e à difícil comunicação com algumas áreas mais distantes), fatores semelhantes aos descritos anteriormente por Hammond et al. ${ }^{24}$.

Vários protocolos são propostos por ser uma doença com diferentes mutações regionais, com diferentes freqüências de aparecimento dos genes da doença. Ainda não há uma uniformização de protocolos entre diferentes países e nem, muitas vezes, em diferentes regiões dentro de um mesmo país.

São poucos os estudos que correlacionam o custo da realização da triagem neonatal com os diagnósticos encontrados. Questiona-se se o treinamento de pediatras para o reconhecimento precoce da doença não teria efeito e resultados semelhantes à realização da triagem neonatal. Como, aqui no Brasil, demora-se em média 4 anos $^{25}$ para realizar o diagnóstico e como isso, em termos de desenvolvimento nutricional, colonização bacteriana e retardo cognitivo pode se tornar catastrófico para o fibrocístico, parecem ser inegáveis os benefícios da triagem neonatal no nosso país. Não há como fazer uma comparação de custos, visto que não é possível medir os custos diretos e indiretos que uma criança com FC sem diagnóstico geraria ao sistema de saúde.

O diagnóstico precoce tem proporcionado aos profissionais que acompanham essas crianças um melhor conhecimento sobre a doença e sua história natural. Aos pais, proporciona um esclarecimento sobre a sua realidade, aos cuidados a serem tomados, principalmente no primeiro ano de vida, bem como a oportunidade de realizar um planejamento familiar. Além disso, a triagem neonatal é uma forma de divulgação sobre FC, uma vez que passa a fazer parte da rotina de interpretação do teste do pezinho para mais de $98 \%$ das crianças nascidas no Paraná.

\section{Referências}

1. Raskin S, Philipps JA, Krishnamani MR, Vneuca K, Jones C, Parker RA, et al. DNA analysis of cystic fibrosis in Brazil by direct PCR amplification from Guthrie Cards. Am J Med Genetics. 1993;46:665-9.

2. Robinson P. Cystic fibrosis. [Review series: Paediatric origins of adult lung disease]. Thorax. 2001;56:237-41.

3. Farias $L$, Rosário NA, Kovalhuk L, Miasaki N, Chaves SM, Recco RA, et al. Aspectos clínicos da fibrose cística. Experiência no Hospital de Clínicas da UFPR, 1980-1996. Pediatria (São Paulo). 1997;19:241-8.

4. Riedi CA, Zavadniak AF, Silva DC, Franco A, Rosário NA. Comparação entre condutividade e sódio na mesma amostra de suor. J Pediatr (Rio J). 2000;76:443-6.

5. Southern KW, Littlewood JM. Newborn screening programmes for cystic fibrosis. Pediatr Resp Rev. 2003;4:299-305.

6. Wilson JM, Jungner G. Principles and practice of screening for disease. Public Health Papers (WHO). 1968;34.

7. Mastela G, Zanolla L, Castellani C, Altieri S, Furnari M, Giglio L, et al. Neonatal screening for cystic fibrosis: Iong term clinical balance. Pancreatology. 2001;1:531-7.

8. Farrell PM, Kosorok MR, Laxova A, Shen G, Koscik R, Bruns WT, et al. Nutritional benefits of neonatal screening for cystic fibrosis. N Engl J Med. 1997;337:963-9.

9. Farrell PM, Kosorok MR, Rock MJ, Laxova A, Zeng L, Lai HC, et al. Early diagnosis of cystic fibrosis through neonatal screening prevents severe malnutrition and improves long-term growth. Pediatrics. 2001;107:1-13.

10. Merelle ME, Schouten JP, Gerritsen J, Dankert-Roelse JE. Influence of neonatal screening and centralized treatment on long-term clinical outcome and survival of CF patients. Eur Resp J. $2001 ; 18: 306-15$.

11. Dankert-Roelse JE, Meerman GJ. Long term prognosis of patients with cystic fibrosis in relation to early detection by neonatal screening and treatment in a cystic fibrosis centre. Thorax. 1995;50:712-18.

12. Castellani $C$. Evidence for newborn screening for cystic fibrosis. Ped Resp Rev. 2003;4:278-84.

13. Wagener JS, Farrell PM, Corey M. A debate on why my state (Province) should or should not conduct newborn screening for cystic fibrosis (14 $4^{\text {th }}$ annual North American Cystic Fibrosis Conference). Pediatr Pulmonol. 2001;32:385-96.

14. Farrell PM, Kosorok MR, Rock MJ, et al. Lung disease in patients with cystic fibrosis diagnosed through neonatal screening or after delays associated with traditional methods [abstract]. Pediatr Pulmonol. 2002;S24:319.

15. Perobelli S, Faraguna D, Giglio L, et al. False positive screening for cystic fibrosis: reactions in parents and attitudes of professionals. Proceedings de conference internationale mucoviscidose, University of Caen, October 5-6 1998. p. 203-14.

16. Castellani C. Extensive genetic analysis for neonatal screening. In: Romano L, Manno G, Galieta LJ. Proceedings of the 25th European Cystic Fibrosis Conference. Bologna: Monduzzi; 2002. p. 77-81.

17. Scotet V, Braekeleer M, Roussey M, Rault G, Parent P, Dagorne $M$, et al. Neonatal Screening for Cystic Fibrosis in Brittany, France: assessment of 10 years' experience and impact on prenatal diagnosis. Lancet. 2000;356:789-94.

18. Lai HC, Kosorok MR, Laxova A, Davis LA, FitzSimmon SC, Farrell PM. Nutritional status of patients with cystic fibrosis with meconium ileus: a comparison with patients without meconium ileus and diagnosed early through neonatal screening. Pediatrics. 2000;105:53-61.

19. Crossley JR, Elliott RB, Smith PA. Dried blood spot screening for cystic fibrosis in the newborn. Lancet. 1979; I:472-4. 
20. Farrel $\mathrm{MH}$, Farrel PM. Newborn screening for cystic fibrosis: ensuring more good than harm. J Pediatr. 2003;143:707-12.

21. Rock MJ, Mischler EH, Farrell PM, Wei LJ, Bruns WT, Hassemer $D$, et al. Newborn screening for cystic fibrosis is complicated by age-related decline in immunoreactive trypsinogen levels. Pediatrics. 1990;85:1001-7.

22. Wilcken B, Wiley V. Newborn screening methods for cystic fibrosis. Pediatr Resp Rev. 2003;4:272-7.

23. Raskin S. Estudo multicêntrico das bases da genética molecular e da epidemiologia da fibrose cística em populações brasileiras [tese]. Curitiba (PR): Universidade Federal do Paraná; 2001.

24. Hammond KB, Abman SH, Sokol RJ, Accurso FJ. Efficacy of statewide neonatal screening for cystic fibrosis by assay of trypsinogen concentrations. New Engl J Med. 1991;325:769-74.
25. Alvarez $A E$, Ribeiro AF, Hessel $G$, Bertuzzo CS, Ribeiro JD. Fibrose cística em um centro de referência no Brasil: características clínicas e laboratoriais de 104 pacientes e sua associação com o genótipo e a gravidade da doença. J Pediatr (Rio J). 2004;80:371-9.

\section{Correspondência:}

Grégor Paulo Chermikoski Santos

Rua Carlos Klemtz, 1410 Bl. 31 Ap.21, Fazendinha

CEP 81320-000 - Curitiba, PR

Tel./fax: (41) 245.7246

E-mail: gpchermi@bol.com.br 